\title{
Perencanaan Geometrik dan Perkerasan Jalan Tol Pandaan-Malang dengan Jenis Perkerasan Lentur
}

\author{
Muhammad Bergas Wicaksono, Istiar \\ Jurusan Teknik Sipil, Fakultas Teknik Sipil dan Perencanaan, Institut Teknologi Sepuluh Nopember \\ Jl. Arief Rahman Hakim, Surabaya 60111 Indonesia \\ e-mail:wicaksono.bergas@gmail.com,istiar@yahoo.com
}

\begin{abstract}
Abstrak - Dengan terus meningkatnya perekonomian di wilayah Jawa Timur terutama perekonomian di dua kota besar yaitu kota Surabaya dan Malang, maka mobilitas atau pergerakan barang dan jasa antara kedua wilayah inipun semakin meningkat. Salah satu bagian jalur yang menghubungkan kota Surabaya dan kota Malang adalah jalur Pandaan-Malang. Jalur ini adalah jalur yang vital dikarenakan banyak kendaraan berat, kendaraan umum seperti bis, serta mobil penumpang yang melewati jalur ini karena jalur ini merupakan jalur utama dan merupakan jalur tercepat untuk menuju kota Surabaya jika dari kota Malang. Oleh karena itu diperlukan adanya jalur alternatif yang menghubungkan Malang-Pandaan dan dipilih jalan tol sebagai jalur alternatif. Penelitian ini berisi tentang penilaian trase alternatif terhadap trase rencana jalan tol milik Bina Marga, perencanaan geometrik, perencanaan tebal perkerasan jalan, kebutuhan akan fasilitas jalan tol, serta besarnya volume pekerjaan. Perencanaan geometrik dilakukan berdasarkan "Tata Cara Perencanaan geometrik Jalan Antar Kota tahun 1997" [1] sedangkan untuk perencanaan tebal perkerasan berdasarkan "Manual Desain Perkerasan Jalan tahun 2013" serta "Petunjuk Perencanaan Tebal Perkerasan Lentur Jalan Raya dengan Metode Analisa Komponen tahun 1987". Dari hasil perencanaan jalan tol ini didapatkan panjang jalan tol $39,523 \mathrm{~km}$ dengan 14 PI dan PPV sebanyak 168. Tebal lapisan perkerasan yang dibutuhkan adalah sebesar $20 \mathrm{~cm}$ untuk lapisan surface dengan bahan Laston $M S=744 \mathrm{~kg}$, $20 \mathrm{~cm}$ untuk lapisan pondasi atas dengan bahan batu pecah kelas A, serta $10 \mathrm{~cm}$ untuk lapisan pondasi bawah dengan bahan sirtu kelas A. Volume timbunan didapatkan sebesar 11.720.504,65 $\mathrm{m}^{3}$ dan volume galian didapatkan sebesar 2.022.332,38 $\mathrm{m}^{3}$.
\end{abstract}

Kata kunci : Perencanaan Geometrik, Perencanaan Perkerasan Jalan, Jalan Tol

\section{PENDAHULUAN}

\subsection{Latar Belakang}

D engan terus meningkatnya perekonomian di wilayah Jawa Timur terutama perekonomian di dua kota besar yaitu kota Surabaya dan Malang, maka mobilitas atau pergerakan barang dan jasa antara kedua wilayah inipun semakin meningkat.

Di sisi lain, belum ada jalur alternatif yang menghubungkan Malang dan kecamatan Pandaan sehingga berbagai jenis kendaraan pun menumpuk di jalur ini. Hal itu menjadikan jalur ini sebagai wilayah rawan kecelakaan dan kecelakaan yang terjadi pun seringkali dialami oleh bus dan kendaraan berat.

Pada sepanjang jalur Pandaan-Malang juga banyak terdapat kawasan industri dari berbagai macam bidang.. Buruh pabrik yang menyeberang jalan ataupun para penjemput yang bergerombol di pintu gerbang pabrik hingga sering hampir memakan badan jalan akan menimbulkan gangguan pada kelancaran arus lalu lintas dan tidak jarang kendaraan-kendaraan yang melambat akibat aktivitas dari buruh pabrik ini akan menimbulkan kemacetan.

Hal lain yang sering dijumpai pada jalur PandaanMalang adalah aktivitas perbaikan jalan. Hal ini dikarenakan tingginya jumlah kendaraan berat yang melalui jalur ini dan tidak jarang kendaraan berat tersebut mengangkut muatan yang melebihi muatan maksimum yang boleh dibawa kendaraan tersebut.

Maka dilatarbelakangi oleh ketiga masalah yang terjadi pada jalur yang menghubungkan kota Malang dengan kecamatan Pandaan itu, Pemerintah Kota malang berencana membangun Jalan Tol Pandaan-Malang sebagai alternatif jalur baru. Dengan adanya jalan tol yang akan dibangun ini, diharapkan masyarakat kini memiliki alternatif yang bisa dipilih dalam melakukan perjalanan baik dari Malang menuju pandaan atau sebaliknya.

\subsection{Perumusan Masalah}

Adapun perumusan masalah dari Penelitian ini adalah:

1. Bagaimana trase jalan tol Pandaan-Malang yang akan direncanakan? 
2. Bagaimana merencanakan geometrik jalan pada jalan tol Pandaan-Malang sesuai dengan Tata Cara Perencanaan Geometrik Jalan Antar Kota?

3. Berapakah perpindahan volume lalu lintas jalan eksisting?

4. Bagaimana merencanakan tebal perkerasan yang akan digunakan pada jalan tol Pandaan-Malang?

5. Berapakah volume pekerjaan jalan tol Pandaan Malang?

\subsection{Tujuan Perencanaan}

Tujuan dari Penelitian adalah:

1. Dapat merencanakan detail geometrik jalan pada jalan tol Pandaan-Malang sesuai dengan Tata Cara Perencanaan Geometrik Jalan Antar Kota.

2. Mengetahui jumlah perpindahan volume lalu lintas dari jalan eksisting

3. Dapat merencanakan trase yang akan dilalui oleh jalan tol Pandaan-Malang.

4. Dapat merencanakan detail struktur tebal perkerasan yang akan digunakan.

5. Mendapatkan volume pekerjaan jalan tol PandaanMalang.

\section{METODOLOGI}

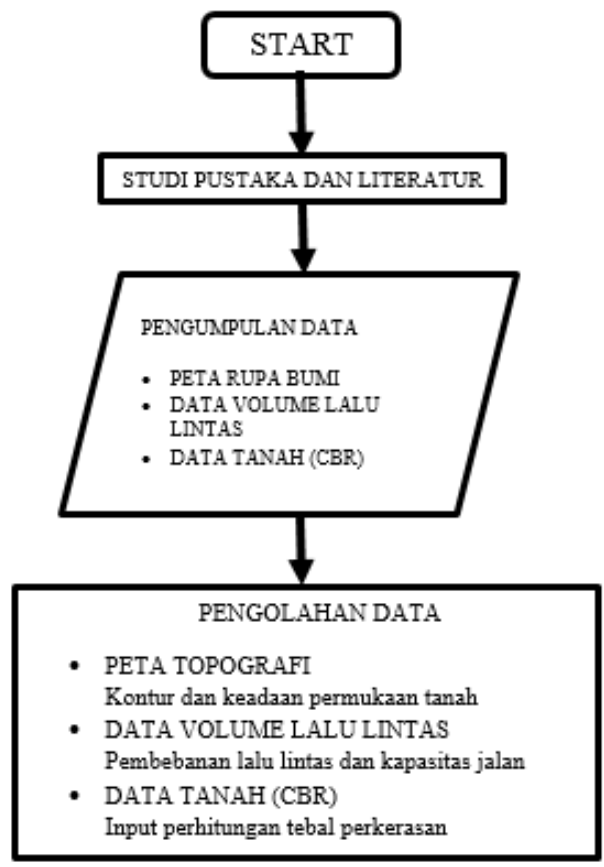

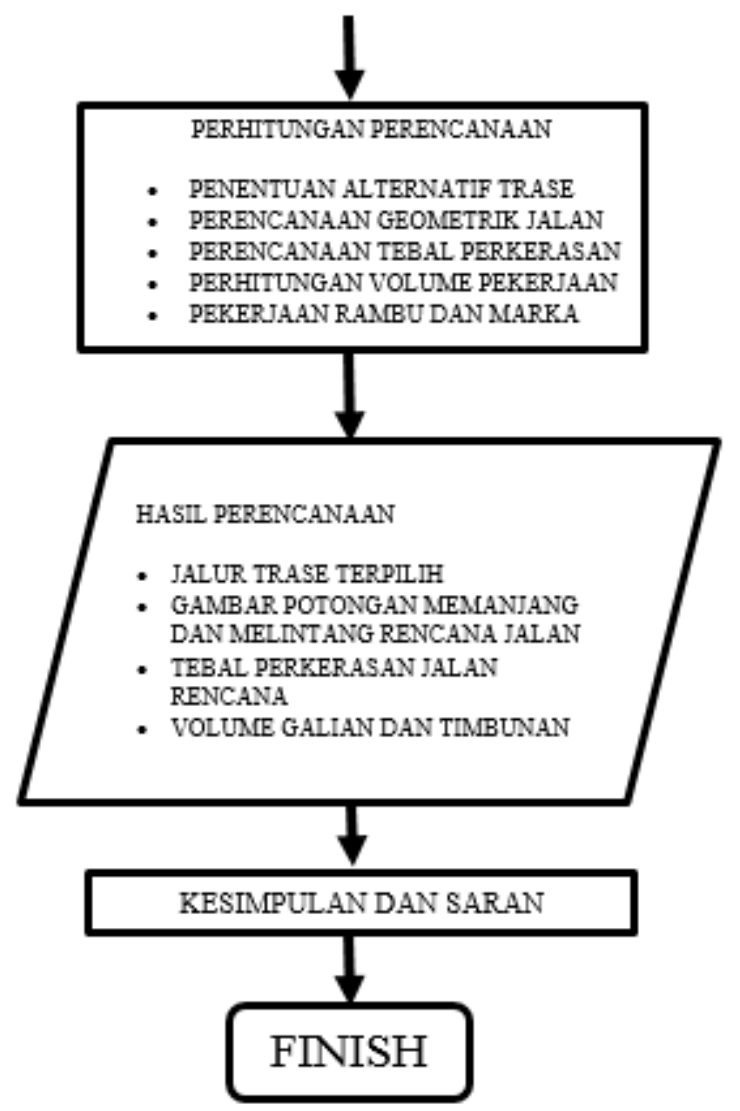

Gambar 1. Diagram alir penelitian

\section{DATA DAN ANALISA DATA}

\subsection{Data Lalu Lintas Harian}

Dari data lalu lintas hasil dan Jalan Pandaan-Malang, diolah menjadi data lalu lintas harian dan diperkirakan menjadi beban bagi jalan tol yang direncanakan.

Tingkat pertumbuhan lalu lintas ini diasumsikan sama dengan tingkat pertumbuhan penduduk dan pertumbuhan ekonomi di wilayah Jawa Timur.

- Pertumbuhan jumlah penduduk menggambarkan pertumbuhan lalu lintas angkutan umum

- Pertumbuhan Produk Domestik Regional Bruto Daerah menggambarkan laju pertumbuhan kendaraan niaga

- $\quad$ Pertumbuhan Produk Domestik Regional Bruto per kapita menunjukkan laju pertumbuhan kendaraan pribadi

\subsection{Data Primer Lalu Lintas}

Data didapat dari survey perhitungan (counting) lalu lintas pada ruas Jalan Raya Surabaya Malang. Survey dilakukan pada hari Senin tanggal 25 April 2016 pada pukul 6.00-22.00.

Pengambilan data dilakukan terhadap 10 golongan kendaraan yaitu golongan 2, 3, 4, 5A, 5B, 6A, 6B, 7A, 7B, dan 7C. 


\subsection{Data Tanah (CBR)}

Data tanah didapatkan dari Laboratorium Mekanika Tanah Institut Teknologi Sepuluh Nopember, seperti sebagai berikut.

\begin{tabular}{|c|c|c|}
\hline $\begin{array}{l}\text { Lokasi } \\
\text { Deskripsi T }\end{array}$ & $\begin{array}{r}\text { : Keca } \\
\text { hah }: \text { Sub- } \\
\text { Tabel } 1 \\
\text { Data Tanah }\end{array}$ & $\begin{array}{l}\text { tan Lawang } \\
\text { de }\end{array}$ \\
\hline \multirow{2}{*}{$\begin{array}{l}\text { Titik } \\
\text { no. }\end{array}$} & \multicolumn{2}{|c|}{ Nilai CBR } \\
\hline & $0,1 "$ & $0,2 "$ \\
\hline 1 & $34.13 \%$ & $36.68 \%$ \\
\hline 2 & $49.20 \%$ & $43.93 \%$ \\
\hline 3 & $19.17 \%$ & $19.00 \%$ \\
\hline 4 & $41.63 \%$ & $45.07 \%$ \\
\hline 5 & $10.43 \%$ & $9.40 \%$ \\
\hline
\end{tabular}

Dari data CBR yang didapatkan dicari besarnya nilai CBR dari persentase sebesar $90 \%$.

\section{ALTERNATIF DAN PEMILIHAN TRASE}

\subsection{Alternatif Trase}

Dalam perencanaannya dibuat alternatif jalur traseyang memenuhi dalam aspek ekonomis.

Kriteria perencanaan trase ini didasarkan pada beberapa kriteria utama, antara lain luasnya lahan yang harus dibebaskan, panjang kumulatif jembatan, dan jumlah persil bangunan yang dibebaskan.

Terdapat dua alternatif pilihan trase yaitu trase milik Bina Marga serta trase alternatif lainnya.

\subsection{Pemilihan Trase}

Dari alternatif-alternatif tersebut akan dipilih satu yang menjadi dasar perencanaan berikutnya.

Kriteria yang dijadikan sebagai bahan pertimbangan adalah sebagai berikut :

1. Luas lahan yang dibebaskan (diasumsikan dengan panjang jalan yang melewati pemukiman dikalikan Ruang Pengawasan Jalan/Ruwasja $=75 \mathrm{~m}$ ).

2. Jumlah bentang jembatan.

3. Jumlah persil bangunan yang dibebaskan.
Tabel 2.

Penilaian setiap trase untuk mendapatkan trase yang terpilih

\begin{tabular}{|c|c|c|c|c|}
\hline \multirow[b]{2}{*}{ Kriteria } & \multicolumn{2}{|c|}{ I } & \multicolumn{2}{|c|}{ II } \\
\hline & & $\begin{array}{l}\text { nil } \\
\text { ai }\end{array}$ & & $\begin{array}{l}\text { nil } \\
\text { ai }\end{array}$ \\
\hline $\begin{array}{l}\text { Panjang } \\
(\mathrm{km})\end{array}$ & 37.618 & & 39.523 & \\
\hline $\begin{array}{l}\text { Jumlah } \\
\text { Persil }\end{array}$ & 677 & 1 & 542 & 2 \\
\hline $\begin{array}{l}\text { Jumlah } \\
\text { Bentang } \\
\text { Jembatan }\end{array}$ & 36 & 1 & 30 & 2 \\
\hline \begin{tabular}{l}
\multicolumn{1}{c}{ Luas } \\
Lahan \\
yang \\
dibebaska
\end{tabular} & $\begin{array}{c}282135 \\
0\end{array}$ & 2 & $\begin{array}{l}29642 \\
25\end{array}$ & 1 \\
\hline & $\begin{array}{c}\text { TOTA } \\
\text { L }\end{array}$ & 4 & $\begin{array}{c}\text { TOTA } \\
\text { L }\end{array}$ & 5 \\
\hline
\end{tabular}

Dari hasil pembobotan didapatkan trase nomor II sebagai trase terpilih karena memiliki skor pembobotan yang lebih tinggi.

\section{PERENCANAAN GEOMETRIK}

\subsection{Kriteria Desain Perencanaan Jalan Tol}

Tabel 3.

Kriteria Desain Perencanaan

\begin{tabular}{|c|c|c|c|}
\hline No & Parameter & Desain & Satuan \\
\hline 1 & Kecepatan Rencana & 100 & $\mathrm{~km} / \mathrm{jam}$ \\
\hline \multirow[t]{7}{*}{2} & Potongan Melintang & & \\
\hline & Lebar Lajur & 3,6 & $\mathrm{~m}$ \\
\hline & Lebar Jalur & 9,2 & $\mathrm{~m}$ \\
\hline & $\begin{array}{l}\text { Tipe } \\
\text { Lebar Median + Bahu } \\
\text { Dalam }\end{array}$ & $4 / 2 \mathrm{D}$ & $\mathrm{m}$ \\
\hline & Lebar Bahu Jalan & 3 & $\mathrm{~m}$ \\
\hline & $\begin{array}{l}\text { Kemiringan Melintang } \\
\text { Normal }\end{array}$ & 2 & $\%$ \\
\hline & Superelevasi Maksimum & 10 & $\%$ \\
\hline 3 & $\begin{array}{l}\text { Jarak Pandang } \\
\text { Jarak Pandang Henti } \\
\text { Minimum }\end{array}$ & 175 & $\mathrm{~m}$ \\
\hline \multirow[t]{3}{*}{4} & $\begin{array}{lr}\text { Parameter } & \text { Alinyemen } \\
\text { Horizontal } & \\
\text { Jari-Jari } & \text { Tikungan }\end{array}$ & & \\
\hline & $\begin{array}{l}\text { Minimum } \\
\text { Panjang } \quad \text { Lengkung }\end{array}$ & 370 & $\mathrm{~m}$ \\
\hline & $\begin{array}{l}\text { Peralihan Minimum } \\
\text { Parameter Alinyamen } \\
\text { Vertikal }\end{array}$ & 75 & $\mathrm{~m}$ \\
\hline 5 & Landai Maksimum & 4 & $\%$ \\
\hline
\end{tabular}




\subsection{Perhitungan Pelebaran Pada Tikungan}

Pelebaran pada tikungan diperlukan karena pengemudi akan sulit dalam mempertahankan lajur lintasan kendaraannya saat melintasi tikungan. [1]

Sesuai dengan tabel pelebaran di tikungan untuk jalan 4 lajur 2 arah pada Tata Cara Perencanaan Geometrik Jalan Antar Kota, Direktorat Jenderal Binamarga, No. 038/TBM/1997, [1] maka pelebaran pada tikungan dapat ditentukan melalui interpolasi

$$
\begin{aligned}
\mathrm{Vd} & =100 \mathrm{~km} / \mathrm{jam} \\
\mathrm{R} & =500 \mathrm{~m} \\
\mathrm{~W} & =0,98 \mathrm{~m} \sim \text { dipakai } 1 \mathrm{~m}
\end{aligned}
$$

\section{PERENCANAAN PERKERASAN JALAN}

\subsection{Analisa Data Lalu Lintas}

Direncanakan umur rencana jalan 10 tahun [2], diperkirakan akan mulai beroperasi pada tahun 2018 dan akhir umur rencana 2028.

Data lalu lintas tahun 2016 yang digunakan adalah data saat peak hour lalu lintas terbesar dengan satuan smp yaitu data lalu lintas pada jalan arteri di wilayah Purwosari untuk arah Utara-Selatan pada pukul 18.0019.00 WIB dan arah Selatan-Utara pada pukul 7.00-8.00 WIB.

Melalui analisa data lalu lintas yang dikorelasikan dengan tingkat pertumbuhan penduduk dan ekonomi Jawa Timur [3], maka dihasilkan tabel LHR sebagai berikut.

Tabel 4. Perhitungan LHR

\begin{tabular}{rccc}
\hline \hline & Arah & $\begin{array}{c}\text { Total } \\
\text { (smp/jam) }\end{array}$ & $\begin{array}{c}\text { LHR } \\
\text { (smp/hari) }\end{array}$ \\
\hline V & U-S & 1610.34 & 14639,45 \\
awal & S-U & 1663.30 & 15120,89 \\
V & U-S & 8453.34 & 76848,56 \\
akhir & S-U & 8534.53 & 77586,63 \\
\hline \hline
\end{tabular}

Berikutnya dari data LHR dilakukan perhitungan data untuk menjadi Lintas Ekivalen Rencana (LER), dengan angka ekivalen sumbu dari tabel EAL, dan angka Koefisien Distribusi kendaraan untuk jalan 4/2 D untuk kendaraan ringan $\mathrm{C}=0,3$ dan untuk kendaraan berat $\mathrm{C}=$ 0,45. Dan melalui metode Smock untuk Trip Assignment, maka didapatkan hasil sebagai berikut

- Arah Utara-Selatan

Jumlah kendaraan tidak berpindah $=$ $\frac{\Sigma \text { Vincrement }}{\Sigma \text { increment }}=\frac{943,816}{2022,46}=47 \%$

Jumlah kendaraan berpindah =

$1-47 \%=53 \%$

- Arah Selatan-Utara
Jumlah kendaraan tidak berpindah = $\frac{\Sigma \text { Vincrement }}{\Sigma \text { increment }}=\frac{927,2667}{1987}=47 \%$

Jumlah kendaraan berpindah =

$1-47 \%=53 \%$

\subsection{Perhitungan Tebal Perkerasan}

Pada perencanaan tebal perkerasan ditentukan Indeks Permukaan IPo $=4,00$ dan IPt $=2,50$ [4].

Untuk mendapatkan Faktor regional digunakan kelandaian di bawah $6 \%$ dengan persentase kendaraan berat lebih dari $30 \%$ [4].

Serta iklim daerah Jawa Timur memiliki curah hujan lebih dari $900 \mathrm{~mm} /$ th sehingga ditentukan FR sebesar $\mathrm{FR}=2,0[4]$.

\subsubsection{Perhitungan CBR Tanah Dasar (Subgrade)}

Perhitungan daya dukung tanah dasar ditetapkan berdasarkan grafik korelasi dari CBR [5]. Perhitungan CBR rencana diperoleh dari nilai CBR rata-rata dari hasil pengujian [5].

Pada persentase $90 \%$ didapatkan nilai CBR sebesar $14,79 \%$. Tidak diperlukan perbaikan tanah karena nilai CBR lebih dari $5 \%$.

Lapisan perkerasan jalan direncanakan untuk arus lalu lintas berat, dimana dipilih bahan untuk setiap lapisan adalah

- Lapisan permukaan (surface) menggunakan Laston (MS $=744 \mathrm{~kg}$ )

- Lapisan pondasi atas (base) menggunakan batu pecah kelas A (CBR 100\%)

- Lapisan pondasi bawah (subbase) menggunakan sirtu kelas A (CBR 70\%)

Tiap lapisan memiliki nilai koefisien kekuatan relatif yaitu

- $\quad$ Lapisan permukaan, a1 $=0,4$

- $\quad$ Lapisan pondasi atas, a2 $=0,14$

- Lapisan pondasi bawah,, a3 =0,13

Sehingga tebal lapisan perkerasan menggunakan ketentuan Bina Marga adalah sebagai berikut:

Untuk arah Utara-Selatan :

- Lapisan Permukaan (surface) Dipakai $\mathrm{D}_{1}=20 \mathrm{~cm}$

- Lapisan Pondasi Atas (base) Dipakai $\mathrm{D}_{2}$ minimum $=20 \mathrm{~cm}$

- Lapisan Pondasi Bawah (subbase) Dipakai $\mathrm{D}_{3}$ minimum $=10 \mathrm{~cm}$

Untuk arah Selatan-Utara :

- Lapisan Permukaan (surface) Dipakai $\mathrm{D}_{1}=15 \mathrm{~cm}$

- Lapisan Pondasi Atas (base) Dipakai $\mathrm{D}_{2}$ minimum $=20 \mathrm{~cm}$

- Lapisan Pondasi Bawah (subbase) Dipakai $\mathrm{D}_{3 \text { MINIMUM }}=15 \mathrm{~cm}$

Gambar lapisan perkerasan dari perhitungan di atas adalah sebagai berikut : 


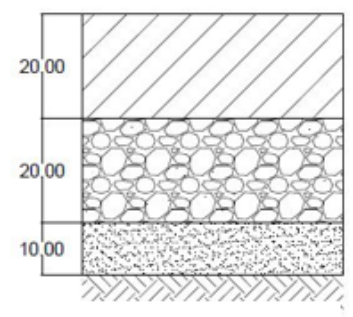

Lapisan Perkerasan

Jalur Utara-Selatan

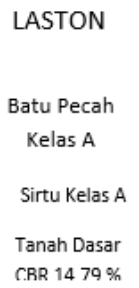

C.RR $1479 \%$

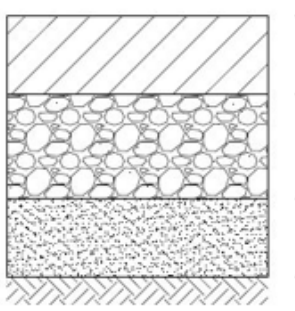

Lapisan Perkerasan

Jalur Selatan-Utara
Gambar 2 Tebal Lapisan Perkerasan

\section{FASILITAS JALAN DAN VOLUME PEKERJAAN}

\subsection{Fasilitas Jalan}

\subsubsection{Rambu Lalu Lintas}

Rambu lalu lintas yang dipasang berdasarkan pada ketentuan yang ada pada Tata Cara Pemasangan Rambu dan Marka Jalan Perkotaan No. 01/P/BNKT/1991. Pada kecepatan rencana $>80 \mathrm{~km} / \mathrm{jam}$, jarak pemasangan antar rambu adalah $350 \mathrm{~m}$.

\subsubsection{Marka Jalan}

Marka Jalan adalah suatu tanda yang berada di permukaan jalan atau di atas permukaan jalan yang meliputi peralatan atau tanda yang membentuk garis membujur, garis melintang, garis serong, serta lambang yang berfungsi untuk mengarahkan arus lalu lintas dan membatasi daerah kepentingan lalu lintas.

\subsection{Volume Pekerjaan}

\subsubsection{Perhitungan Volume Pekerjaan}

Volume dari beberapa item pekerjaan tersebut didapatkan melalui analisa oleh aplikasi Autocad Civil 3D.

a. Pekerjaan Badan dan Bahu Jalan

A = Lebar Ruang Milik Jalan $\mathrm{x}$ Panjang Jalan

$$
=24,2 \times 39.532,27
$$

$$
=956680,934 \mathrm{~m}^{2}
$$

b. Lapis Pondasi Bawah, Sirtu kelas A Didapat dari analisa Autocad Civil 3D $\mathrm{V}=173.577,81 \mathrm{~m}^{3}$

\section{c. Lapis Pondasi Atas, Batu Pecah Kelas A} Didapat dari analisa Autocad Civil 3D $\mathrm{V}=183.387,99 \mathrm{~m}^{3}$

d. Laston untuk Lapis Permukaan Didapat dari analisa Autocad Civil 3D $\mathrm{V}=183.387,99 \mathrm{~m}^{3}$

e. Prime Coat, diperlukan $1,3 \mathrm{liter} / \mathrm{m}^{2}$

$\mathrm{V}=$ Luas Jalan $\mathrm{x}$ Volume Prime Coat per $\mathrm{m}^{2}$ $=1243685,2142$ liter

f. Tack Coat, diperlukan $0,4 \mathrm{lt} / \mathrm{m}^{2}$

$\mathrm{V}=$ Luas Jalan $\mathrm{x}$ Volume Prime Coat per $\mathrm{m}^{2}$ $=956680,934 \mathrm{~m}^{2} \times 0.4$ liter $/ \mathrm{m}^{2}$

$$
=382672,3736 \text { liter }
$$

\section{g. Galian dan Timbunan Tanah}

Didapat dari analisa Autocad Civil 3D

Total Volume Galian $=2022332,38 \mathrm{~m}^{3}$ Total Volume Timbunan $=11720504,65 \mathrm{~m}^{3}$

\section{h. Drainase Jalan}

Didapat dari analisa Autocad Civil 3D

Total Volume Drainase $($ U-Ditch $)=36204,33 \mathrm{~m}^{3}$ Total Volume Lid (Penutup Drainase) $=8299,89 \mathrm{~m}^{3}$

i. Fasilitas Jalan

- Marka Jalan (Putus-Putus)

$\begin{array}{ll}\text { Jarak antara } & : 8 \text { meter } \\ \text { Lebar } & : 0,15 \mathrm{~m} \\ \text { Panjang } & : 3 \text { meter } \\ \text { V } & =2736,23 \mathrm{~m}^{2}\end{array}$

- Marka Jalan (Garis Utuh) Lebar $\quad: 0,15 \mathrm{~cm}$ Jumlah dalam satu jalur $: 2$ $\mathrm{V}=0,15 \times 39523,27 \times 4=23713,96 \mathrm{~m}^{2}$

- Median Jalan

Didapat dari analisa Autocad Civil 3D $\mathrm{V}=173.577,81 \mathrm{~m}^{3}$

- Rambu

Jumlah rambu : 88 buah

- Patok Hektometer

Patok hektometer dipasang di setiap jarak $100 \mathrm{~m}$ Jumlah $:(39.523,27 / 100)+1=396,23 \sim 396$ buah

\section{- Lampu Penerangan Jalan}

Berdasarkan tabel klasifikasi lampu di SNI 7391:2008, maka dipilih lampu dengan tingkat pencahayaan 20 LUX dan dengan lebar jalan 9,2 meter maka dipilih jarak antar lampu sebesar 30 meter

$$
\text { Jumlah }:(39.523,27 / 100)+1=
$$

$$
1317,43 \sim 1318 \text { buah }
$$

\subsection{Kesimpulan \\ VIII. KESIMPULAN DAN SARAN}

Berdasarkan perencanaan yang telah dibahas pada bab-bab sebelumnya, maka didapatkan kesimpulan sebagai berikut :

1. Pada tahap perencanaan dan pemilihan trase dipilih trase yang memiliki nilai pembobotan lebih tinggi yaitu trase alternatif (Trase nomor II)

2. Trase alternatif yang dipilih memiliki panjang $39,523 \mathrm{~km}$. Jalan tol Pandaan-Malang ini didesain dengan kecepatan rencana $100 \mathrm{~km} / \mathrm{jam}$. Tipe jalan tol ini adalah 4/2 D.

3. Perencanaan geometrik yang dihitung meliputi perencanaan alinyemen horizontal, perencanaan alinyemen vertikal, perhitungan daerah kebebasan samping. Pada perencanaan alinyemen horizontal didapatkan PI sebanyak 14 dengan radius minimum $500 \mathrm{~m}$. dan pada perencanaan alinyemen vertikal didapatkan PPV sebanyak 168 dengan kelandaian maksimum direncanakan $4 \%$.

4. Perencanaan perkerasan jalan dilakukan menggunakan Metode Analisa Komponen. Dengan umur rencana 10 tahun. Data primer diambil pada pukul 6.00-22.00 dan didapatkan peak hour untuk arah Utara-Selatan adalah pukul 18.00-19.00 dan 
peak hour untuk arah Selatan-Utara adalah pukul 7.00-8.00

5. Tebal lapisan perkerasan yang didapatkan dari perhitungan perencanaan adalah sebagai berikut :

a. Untuk jalur arah Pandaan didapatkan

- Lapisan permukaan (surface) Laston MS=744 $\mathrm{kg}$ dengan tebal $15 \mathrm{~cm}$

- Lapisan pondasi atas (base course) batu pecah kelas A dengan tebal $20 \mathrm{~cm}$

- Lapisan pondasi bawah (subbase course) sirtu kelas A dengan tebal $15 \mathrm{~cm}$

b. Untuk jalur arah Malang didapatkan

- Lapisan permukaan (surface) Laston MS=744 kg dengan tebal $20 \mathrm{~cm}$

- Lapisan pondasi atas (base course) batu pecah kelas A dengan tebal $20 \mathrm{~cm}$

- Lapisan pondasi bawah (subbase course) sirtu kelas A dengan tebal $10 \mathrm{~cm}$

Dengan mempertimbangkan kemudahan pekerjaan maka tebal lapisan perkerasan untuk kedua arah disamakan dengan lapisan untuk arah Utara-Selatan yaitu

\subsection{Saran}

Berdasarkan analisa selama proses penyusunan penelitian ini, beberapa saran yang dapat penulis sampaikan adalah :

1. Dalam merencanakan pembangunan jalan tol, pemilihan trase dengan kondisi topografi yang dominan datar serta tidak berbukit akan lebih menguntungkan karena akan lebih memudahkan perencana dalam memenuhi syarat kelandaian serta lebih ekonomis dalam kebutuhan akan galian dan timbunan.

2. Pemilihan bahan material untuk perkerasan jalan sebaiknya juga mempertimbangkan ketersediaan bahan tersebut di daerah sekitar pembangunan jalan tol.

\section{DAFTAR PUSTAKA}

[1] Dep. PU. 1997. Tata Cara Perencanaan Geometrik Jalan Antar Kota. Dirjen Bina Marga. Jakarta

[2] Sukirman, Silvia. 1999. Dasar-Dasar Perencanaan Geometrik Jalan. Penerbit Nova. Bandung

[3] Dep. PU. 2009. Standar Geometri Jalan Bebas Hambatan untuk Jalan Tol. Dirjen Bina Marga. Jakarta

[4] Dep. PU. 1987. Petunjuk Perencanaan Tebal Perkerasan Lentur Jalan Raya dengan Metode Analisa Komponen. Dirjen Bina Marga. Jakarta

[5] Dep. PU. 2013. Manual Desain Perkerasan Jalan. Dirjen Bina Marga. Jakarta 